\title{
PURUSHOTTAM MASS (AN EXTRA MONTH IN HINDU CALANDER)
}

\section{MADAN MOHAN NAURIYAL}

Government Intermediate College, Parsundakhal, Pauri Garhwal, Uttarakhand

*Corresponding Author Email: madanmohan20863@gmail.com

Received: 2.9.2020; Revised: 12.10.2020; Accepted: 28.10.2020

CSociety for Himalayan Action Research and Development

\begin{abstract}
Two types of years are described in Indian calculation method astrology, the sun year and the moon year. Sun year is 365 days and 6 hours long and the lunar year is considered to be of 354 days. If we calculate the difference between two years, it comes to be of 11 days and it becomes roughly one month in three successive years. Thus one lunar month comes extra into existence. This month is called as "Purushottam maas", "Adhik mas" or an extra month. The overlord of this month is considered as "Lord Krishna" who was also born in this month.The present paper depicts the analysis of this extra month in view of "Shri Mad Bhagwat Mahapuran" and other literary scripts.
\end{abstract}

Keywords: Extra Month, Shrimad Bhagwat Puran, Analysis

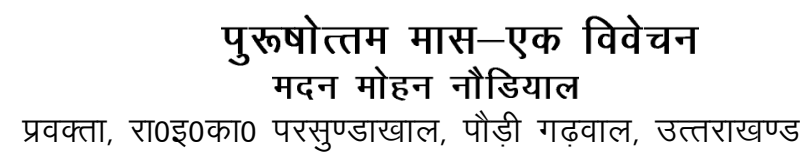

सारांश

भारतीय गणना पद्यति ज्योतिश शास्त्र में दो प्रकार के वर्षो का वर्णन मिलता है। एक सूर्य वर्ष तथा दूसरा चन्द्र वर्ष। सूर्य वर्ष 365 दिन व करीब 6 घण्टे का होता है और चन्द्र वर्ष 354 दिनों का माना गया है, दोनो वर्षो का यदि हम अन्तर करें तो यह अन्तर 11 दिन का होता है, और तीन वर्ष में लगभग 1 माह का अन्तर होता है। एक चन्द्र वर्ष माह अस्तित्व में आता है। इसी अतिरिक्त मास को अधिकमास, मलिन मास या पुरूषोत्तम मास कहा जाता है, और इस मास के अधिपति भगवान कृष्ण को माना जाता है। भगवान कृष्ण का जन्म भी चन्द्रवर्ष में हुआ था। कोई भी देवता इस अतिरिक्त मास को अपने ऊपर नही लेना चाहता था। सम्पूर्ण देवताओं के विनय करने पर स्वयं वहन किया, वशिष्ठ सिद्धान्त में सूर्य वर्ष व चन्द्र वर्ष दोनों का अन्तर देखने को मिलता है।

कुंजी शब्द : मलमास, अधिकमास, श्रीमद्भागवत पुराण, विश्लेषण

भारतीय गणना पद्यति के अनुसार प्रत्येक सूर्य वर्ष 365 दिन और करीब 6 घण्टे का होता है। वही चन्द्रवर्ष 354 दिनों का माना जाता है। दोनो वर्षों के बीच लगभग 11 दिनों का अन्तर होता है। जो हर तीन वर्षों मे लगभग एक मास के बराबर हो जाता है। इसी अन्तर को पाटने के लिए हर तीन साल में एक चन्द्रमास अस्तित्व मे आता है, जिसे अतिरिक्त होने के कारण अधिकमास, मलमास या पुरूषोत्तम मास के नाम से जाना जाता है। सनातन धर्म में इसका विशेष महत्व है। सम्पूर्ण भारत में इस पूरे मास मे पूजा पाठ, भगवत् भक्ति, व्रत उपवास, जप और योग, धार्मिक कार्य किये जाते हैं। धार्मिक मान्यता है कि अधिकमास में किये गये धार्मिक कार्यों का दस गुना फल प्राप्त होता है। श्रद्धालु भगवान को प्रसन्न करने के लिए पुरी श्रद्धा 
व भक्ति के साथ इहलोक और परलोक सुधारते हैं। वशिष्ठ सिद्धान्त के अनुसार भारतीय ज्योतिष सूर्य मास और चन्द्रमास की गणना के अनुसार चलता है, अधिकमास या पुरूषोत्तम मास 32 माह 16 दिन और 8 घडी के अन्तर में आता है, इसका प्राकाट्य सूर्य वर्ष और चन्द्र वर्ष के बीच के अन्तर का सन्तुलन करने के लिए होता है। अधिकमास या पुरूषोत्तम मास के स्वामी भगवान कृष्ण हैं। पुरूषोत्तम भगवान कृष्ण का एक नाम है।

श्रीमद्भागवत महापुराण में भगवान कृष्ण को पुरूषोत्तम नाम से ऋषियों द्वारा सम्बोधन किया गया है-

\section{"त्वं नस्तप: परममात्थ यदात्मतेजो ${ }^{1}$ \\ यनेद मादि पुरूषात्मगतं संसर्ज: \\ तद् विप्रलुप्तममुनाद्य शरण्यपाल \\ रक्षा गृहीत व पुशा: पुनरन्वमंसथा:"}

अर्थात् पुरूषोत्तम अपने तपस्या के द्वारा ही अपने में लीन हुए जगत की फिर से रचना की थी और कृपा करके उसी आत्मतेजः स्वरूप श्रेष्ठ तपस्या का उपदेश आपने हमारे लिए भी किया था, इस दैत्य (हिरण्यकशिपु) ने उसी तपस्या का उच्छेद कर दिया था शरणागतवत्सल! उस तपस्या की रक्षा के लिए अवतार ग्रहण करके आपने हमारे लिए फिर से उसी उपदेश का अनुमोदन किया है।

अतिरिक्त मास या मलमास या खरमास या पुरूषोत्तम मास का अधिपति बनने के लिए कोई देवता तैयार नही हुआ, ऋषियों ने भगवान श्रीकृष्ण से आग्रह किया कि वे इस मास का भार अपने ऊपर लें, और भगवान कृष्ण ने अपनी स्वीकृति देते ही मलमास, पुरूषोत्तम मास बन गया। सांकेतिक अर्थ में यह मास तनमन से पवित्र होने का समय है, श्रद्धालु व्रत, उपवास, ध्यान योग, भजन कीर्तन में संलग्न होकर सामान्य पुरूष से उत्तम पुरूष बनकर अपने मन का मैल धोते हैं। पी०वी० काणे का मत है कि आंग्ल काल की गणना लीप एअर में फरवरी 28 की जगह 29 दिन की हो जाती है। यही भारतीय गणनानुसार तीन वर्ष में बढकर 1 माह हो जाता है। इस माह को भारतवर्ष के राज्यों में अलग-अलग नामें से जाना जाता है, यथा महाराष्ट्र में लोंद का महीना, कई राज्यों में यथा पंजाब में खरमास, डोडामास आदि नामों से जाना जाता है। संक्षेप में मलमास 12 माह में बचे समयकाल का मल है। पुरूषोत्तम मास या मलमास की कथा का पौराणिक आधार हिरण्यकश्यप के वध से जुडी है कथा विस्तृत रूप से श्रीमद्भागवत महापुराण में स्पष्ट परिलक्षित होती है। पौराणिक आधार पर हिरण्यकशिपु ने ब्रहमाजी की कठिन तपस्या की थी

\section{"हिरण्यकशिपू राजन्नजेयम जराभरम् आत्मानम् प्रति द्वन्द मेकराजं व्यधित्सत्"}

अर्थात् हिरणकशिपु ने यह विचार किया कि मैं अजेय, अजर, अमर और संसार का एकक्षत्र सम्राट बन जाऊँ जिससे कोई मेरे सामने खडा न हो सके।

\section{"स तेपे मन्दरद्रोण्यां तपः परम दारूणम्} ऊर्ध्ववाहुर्नशोदृष्टि: पादाडश्ठाश्रितावनि:।"

अर्थात् इसके लिए वह मन्दरांचल की एक घाटी में जाकर अत्यन्त दारूण तपस्या करने लगा, वहाँ वह हाथ ऊपर उठाकर आकाश की ओर देखता हुआ वह पैर के अंगूठे के बल पृथ्वी पर खडा हो गया और हिरण्यकशिपु की कठिन तपस्या से प्रसन्न होकर ब्रहमाजी वरदान देने हेतु प्रस्तुत हुए, उन्होने कहा कि -

ब्रहमोवाच,

"उत्तिष्ठोत्तिष्ठ भद्रं ते तप: सिद्धोऽसि काश्यप: ${ }^{3}$ वरदोऽहमनु प्राप्तो व्रियतामीप्सितो वर:"

ब्रहमाजी बोले- बेटा हिरण्यकशिपु उठो, उठो तुम्हारा कल्याण हो गया है। में तुम्हे वर देने के लिए आया हूँ। तुम्हारी जो इच्छा हो, बेखटके मांग लो।

\section{" नैतत्पूर्वर्षयश्रचः कुर्त करष्यिन्ति चापरे। \\ निरम्बुर्धायेत्प्राणान् को वै दिव्यसमा:शतम्"}

ऐसी कठिन तपस्या न तो पहले किसी ऋषि ने की थी और न आगे ही कोई करेगा, भला ऐसा कौन है जो देवताओं के सौ वर्षों तक बिना पानी के जीता रहे, हिरण्यकशिपु ने ब्रहमा जी से कहा 
यदि दास्यस्यभिमतान् वरान्मे वरदोत्तम: ${ }^{4}$

भूते भ्यस्त्वद्विसृश्ठेभ्यों मृत्युर्मा भून्मम् प्रभो

नान्तर्वहिर्दिवा नक्तमन्यस्मादपि चायुधै।

न भूमो नाम्बरे मृत्युर्न नरैर्न मृगैरपि

व्यसुभिर्वा सुभद्विर्व सुरासुर महो रगै:

अप्रतिद्वन्दतां युद्धे ऐकपत्यं च देहिनाम

सर्वेशां लोकपालनां महिमानं यथाडात्मन:

तपोयोग प्रभावाणां यन्नरिश्यति कर्हिचित

अर्थात हे प्रभो आप समस्त वरदाताओं में श्रेष्ठ है, यदि आप मुझे अभीष्ठ वर देना चाहते हैं तो ऐसा वर दीजिये कि आपके बनाये हुए किसी भी प्राणी से चाहे वह मनुष्य हो या पशु प्राणी हो या अप्राणी देवता हो या दैत्य अथवा नागादि से किसी से भी मेरी मृत्यु न हो, भीतर बाहर, दिन में, रात्रि में आपके बनाये प्राणियों के अतिरिक्त और भी किसी जीव से, अश्त्र -शस्त्र से पृथ्वी या आकाश में, कहीं भी मेरी मृत्यु न हो, युद्ध में कोई मेरा सामना न कर सके। मैं समस्त प्राणियों का एकक्षत्र सम्राट होऊँ। इन्द्रादि समस्त लोकपालों में जैसी आपकी महिमा है वैंसी ही मेरी भी हो। तपस्वियों और योगियों को जो अक्षय ऐश्वर्य प्राप्त है वही मुझे भी दीजिए। ब्रहमाजी ने "तथास्तु" कह हिरण्यकशिपु को इच्छित वर दिया, लेकिन मृत्यु तो अटल सत्य है। उसके वध के लिए भगवान ने नृसिंह रूप धारण किया था और उस समय न दिन था और न रात थी गोधुली समय था, न वह घर के अन्दर था न बाहर, देहरी पर था। भगवान ने कोई अश्त्र भास्त्र धारण नही किया था अपने नाखूनों से उसका पेट फाड डाला, फिर नृसिंह ब्रहमाजी की सृष्टि में भी नही आते हैं, वे मुख से शेर और शरीर से मनुष्य थे। बारह माह में भी उसकी मृत्यु नही हुई बल्कि व यही पुरूषोत्तम मास या मलमास या अतिरिक्त मास था श्रीमद् भागवत् में भगवान के स्वरूप का इस प्रकार वर्णन है।

\section{सत्यं विधातुं निजभृत्यभाशित ${ }^{-5}$ व्याप्तिं च भूतेश्व अखिलेशु चात्मन: अदृश्यताद्धेतरूपं मुद्धहनं \\ स्तम्भे सभायां न मृगंन मानुषम्}

भगवान नृसिंह सेवक प्रहलाद और ब्रहमाजी की वाणी सत्य करने और समस्त पदार्थ में अपनी व्यापकता दिखाने के लिए सभा के भीतर उसी खम्भे मे बडा ही विचित्र रूप धारण करके भगवान प्रकट हुए। वह रूप न तो पूरा-पूरा सिंह का था न ही मनुष्य का था। अतः समस्त जड चेतन में ईश्वर पुरूषोत्तम श्रीकृष्ण का वास है। यथा

यस्मात्क्षर मतीतोडहमछरादपि चोत्तम: ${ }^{8}$

अतोडस्मि लोके वेदे च प्रथितः पुरूषोत्तमः

अर्थात- श्रीकृष्ण कहते हैं कि मैं नाशवान जड वर्ग क्षेत्र से तो सर्वथा अतीत हूँ और अविनाशी जीवात्मा से भी उत्तम हूँ इसलिए लोक में और वेद में भी पुरूषोत्तम नाम से प्रसिद्ध हूँ। सनातन संस्कृति व धर्म के अनुसार प्रत्येक साधक को मलिन मास या पुरूषोत्तम मास में भगवान श्रीकृष्ण का पुरूषोत्तम योग नाम का श्रीमद् भागवद् गीता का 15 वाँ अध्याय पढ़ना चाहिए। इससे अभीष्ट फल की प्राप्ति होती है।

\section{सन्दर्भ ग्रंथ}

1 श्रीमद् भागवत महापुराण (लेखक महर्षि वेद व्यास), गीता प्रेस गोरखपुर सप्तम स्कन्ध, पृष्ठ सं० 713,43 वाँ श्लोक

2 श्रीमद् भागवत महापुराण (लेखक महर्षि वेद व्यास), गीता प्रेस गोरखपुर सप्तम स्कन्ध, पृष्ठ सं० 681, श्लोक सं० 12

3 श्रीमद् भागवत महापुराण (लेखक महर्षि वेद व्यास), गीता प्रेस गोरखपुर सप्तम स्कन्ध, पृष्ठ सं० 682, श्लोक सं० 17,19

4 श्रीमद् भागवत महापुराण (लेखक महर्षि वेद व्यास), गीता प्रेस गोरखपुर सप्तम स्कन्ध, पृष्ठ सं० 
Himalayan J. Soc. Sci. \& Humanities ISSN: 0975-9891

Vol. 15, (2020) 59-62

DOI: https://doi.org/10.51220/hjssh.v15i1.8

684,685 श्लोक सं० $35,36,37$

5 श्रीमद् भागवत महापुराण (लेखक महर्षि वेद व्यास), गीता प्रेस गोरखपुर सप्तम स्कन्ध, पृष्ठ 709 श्लोक सं० 18

6 श्रीमद् भागवत महापुराण (लेखक महर्षि वेद व्यास), गीता प्रेस गोरखपुर सप्तम स्कन्ध, अध्याय 15 श्लोक सं० 18

7 पी०वी० काणे धर्मशास्त्र का इतिहास

8 डा० दामोदर प्रसाद शास्त्री कालमाध्व, स्मृति कौसतुभ, निर्णय सागर 